\title{
Relationship between payment methods for restorations and their age at replacement
}

\author{
Influence of the method of funding on the age of failed restorations in general dental practice in the UK
}

F. J. T. Burke, N. H. F. Wilson, S. W.Cheung and I. A. Mjör Br Dent J 2002; 192: 699-702

\section{Objective}

This study examined the effect of the method of funding treatment on the age of restorations at the time of replacement.

\section{Method}

A group of general dental practitioners were recruited to take part in the study. Each participant was asked to record the reason for placement and replacement of restorations. The age and class of the restoration being replaced was also recorded, together with details of the material being used and the material being replaced. Details of the method of payment of the failed restoration were recorded.

\section{Results}

Details of the reason for placement/replacement were received for 3,196 restorations from 32 GDPs. Of the restorations placed, 54\% were amalgam, 32\% composite, 8\% compomer and 7\% glass ionomer. The age of restorations at the time of replacement was significantly associated with the method of payment for the restoration, with restorations placed in the Armed Forces having been in service significantly longer at the time of their replacement than restorations placed under NHS regulations.

\section{Conclusion}

Statistical analysis indicated that restorations placed within the NHS regulations were replaced at a significantly lower age than restorations placed under the other funding arrangements investigated.

\section{IN BRIEF}

- Restorations placed within the NHS regulations were replaced at a significantly lower age than restorations placed under the other funding arrangements investigated.

- There may be many reasons for this finding, including patient factors, such as poorer oral hygiene for NHS patients than private patients, or different dentist attitudes.

- The most prevalent reason for replacement of restorations was secondary caries. The funding of the restoration had no influence on this.

- Composite materials were more frequently used within the private and private/capitation arrangements.

- The practitioners involved in the study felt that the data were easy to collect, and further studies of this type would appear appropriate.

\section{COMMENT}

This paper is from the Ivar Mjör stable. Professor Mjör has for many years, organised groups of researchers around the world to investigate the longevity of restorations and reasons given by dentists for replacing them. The common feature of this valuable work is that the data collection is carried out in the real world of general practice.

The present work investigated whether there was any relationship between the method of payment for the original restorations and the age they were replaced at. The dentists involved were working under private contract, in insurance/private capitation schemes, under the National Health Service or as salaried dentists in the Armed Forces. It should be noted that apart from the Armed Forces dentists, all the dentists provided treatment under more than one method of funding. In this respect the study was controlled with respect to the skill of the dentists.

Thirty-two practitioners gathered data on 100 patients each. Their commitment was substantial because for each restoration they had to note why they had deemed the restoration a failure, the payment method when it was originally placed and how long it had lasted. This must have involved a considerable time commitment searching back through the records. It is so important to carry out research like this in a real practice situation. Some will only accept evidence from double blind, randomised clinical trails but these are often carried out in dental schools where environments are about as different from general practice as chalk from cheese. It worries me that some of those who trumpet the importance of evidence- based dentistry are downright snooty about pragmatic studies like this and produce guidelines and recommendations based only on work from environments that bear little resemblance to the real world. So sincere thanks to the practitioners and congratulations to the academics who have the sense to work in this way.

Having got that of my chest, I must briefly comment on the findings. The funding method was relevant to the age of the restorations at replacement. Restorations placed under private contract, private insurance schemes and in the Armed Forces were found to perform significantly better in terms of age at replacement than restorations placed under NHS regulations. Perhaps this is what we would have expected and the discussion speculates on possible reasons for this. Since all the dentists, except those in the Armed Services, provided data from more than one method of remuneration, one has to say that the time pressures of the NHS regulations seem likely to be relevant to the longevity of the restorations.

Edwina Kidd

Professor of Cariology, GKT 